
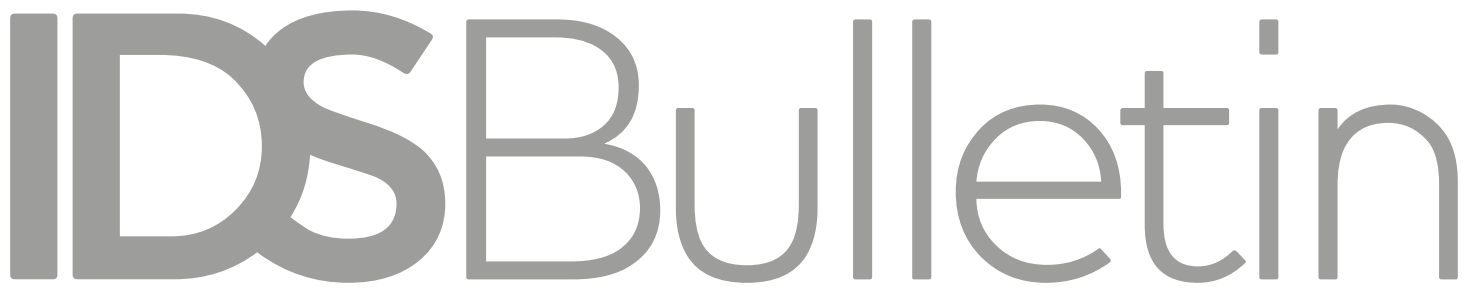

Transforming

Development Knouledge

Volume 49 | Number 2 | March 2018

\title{
ACCOUNTABILITY \\ FOR HEALTH EQUITY: \\ GALVANISING A \\ MOVEMENT FOR \\ UNIVERSAL HEALTH \\ COVERAGE
}

Editors Erica Nelson,

Gerald Bloom and Alex Shankland

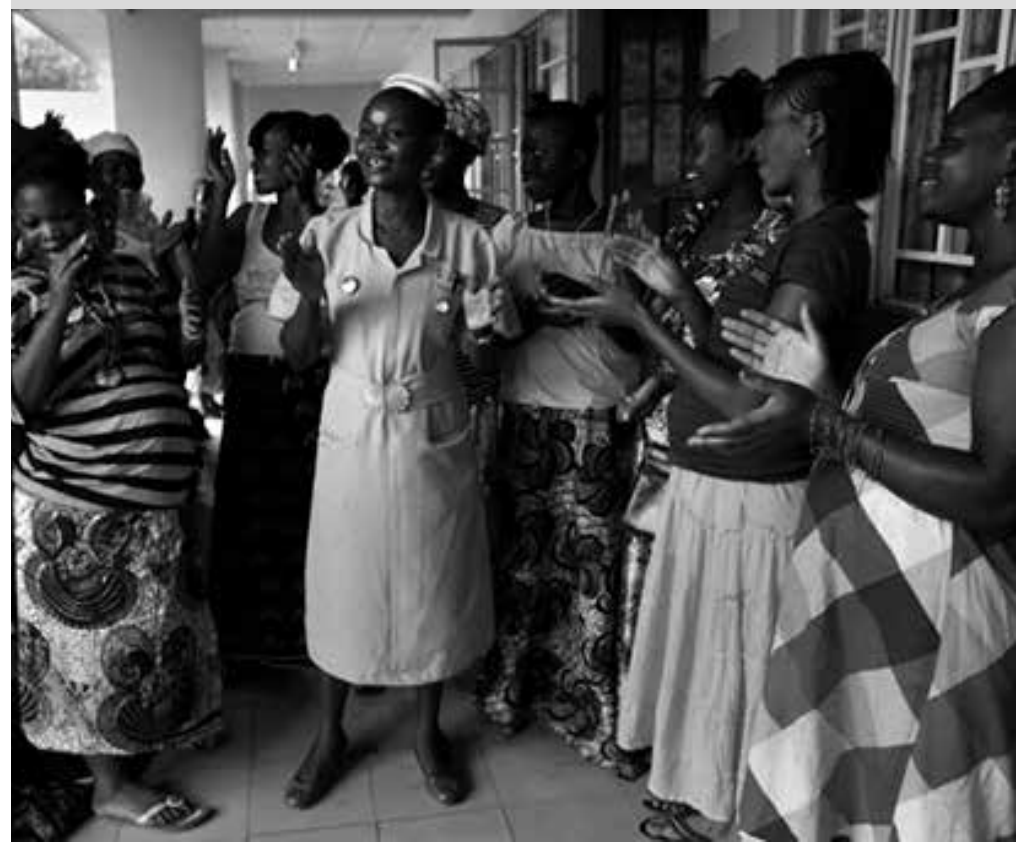


Notes on Article Contributors

Notes on Multimedia Contributors

Foreword

The International Health Partnership for UHC 2030 (UHC2030) Core Team

Introduction: Accountability for Health Equity: Galvanising a Movement for

Universal Health Coverage

Erica Nelson, Gerald Bloom and Alex Shankland

Introduction to Multimedia

Sophie Marsden, Karine Gatellier and Sarah King

Vaishali Zararia, Renu Khanna and Sophie Marsden

Denise Namburete and Erica Nelson

Health Accountability for Indigenous Populations: Confronting Power through Adaptive Action Cycles

Walter Flores and Alison Hernández

Inverted State and Citizens' Roles in the Mozambican Health Sector

Jose Dias and Tassiana Tomé

Accountability and Generating Evidence for Global Health: Misoprostol in Nepal Jeevan Raj Sharma, Rekha Khatri and lan Harper

The Political Construction of Accountability Keywords

Jonathan Fox

\section{Key Considerations for Accountability and Gender in Health Systems in Low- and Middle-Income Countries}

Linda Waldman, Sally Theobald and Rosemary Morgan

Gendered Dimensions of Accountability to Address Health Workforce Shortages in Northern Nigeria

Fatima Lamishi Adamu, Zainab Abdul Moukarim and Nasiru Sa'adu Fakai

Reducing Health Inequalities in Brazil's Universal Health-Care System:

Accountability Politics in São Paulo

Vera Schattan Coelho

Making Private Health Care Accountable: Mobilising Civil Society and Ethical Doctors in India

Abhay Shukla, Abhijit More and Shweta Marathe

Neglected Tropical Diseases and Equity in the Post-2015 Health Agenda

Emma Michelle Taylor and James Smith

Glossary 


\title{
Key Considerations for Accountability and Gender in Health Systems in Low- and Middle-Income Countries"
}

\author{
Linda Waldman, ${ }^{1}$ Sally Theobald ${ }^{2}$ and \\ Rosemary Morgan ${ }^{3}$
}

\begin{abstract}
This article poses questions, challenges, and dilemmas for health system researchers striving to better understand how gender shapes accountability mechanisms, by critically examining the relationship between accountability and gender in health systems. It raises three key considerations, namely that: (1) power and inequities are centre stage: power relations are critical to both gender and accountability, and accountability mechanisms can transform health systems to be more gender-equitable; (2) intersectionality analyses are necessary: gender is only one dimension of marginalisation and intersects with other social stratifiers to create different experiences of vulnerability; we need to take account of how these stratifiers collectively shape accountability; and (3) empowerment processes that address gender inequities are a prerequisite for bringing about accountability. We suggest that holistic approaches to understanding health systems inequities and accountability mechanisms are needed to transform gendered power inequities, impact on the gendered dimensions of ill health, and enhance health system functioning.
\end{abstract}

Keywords: accountability, gender, health systems, power, empowerment.

\section{Introduction}

Accountability and gender are both critical dimensions of health systems. ${ }^{4}$ There is a long, rich, and detailed analysis of the role of gender in health systems which, since it emerged in the 1970s, has examined the visibility and legitimation of women's health issues, the significance of gender as a social determinant of health, and the promotion of policies and other interventions to address gender-related challenges and inequities (see, for example, Alvarez-Dardet and Vives-Cases 2012). Gender is conceptualised as the 'socially constructed roles, behaviours, activities and attributes that a given society considers appropriate for men and women' and people of other genders (WHO 2016), and has 
been shown to create differential health systems' needs, experiences, and outcomes (Morgan et al. 2016; Theobald et al. 2017). In contrast, the emphasis on the concept of accountability within the health system is relatively new (Brinkerhoff 2003; Cleary, Molyneux and Gilson 2013). Consequently, there has been little work which brings together these two bodies of work from a health systems strengthening perspective; and this is an important gap that needs addressing.

Within health systems, accountability 'refers to the processes by which those with power in the health sector engage with, and are answerable to, those who make demands on it, and enforce disciplinary action on those in the health sector who do not perform effectively' (Murthy 2008: 1). The advantages of an accountability agenda include ensuring that health system resources are appropriately used, that positions are allocated to trained and skilled personnel, and that health systems continuously strive for enhanced performance and learning (Brinkerhoff 2004). The focus is primarily on governments' provision of health services. Accountability mechanisms operate at multiple levels and provide tools for holding governments and health sectors accountable to international agreements and instruments (Murthy 2008), yet tend not to engage with informal markets, private sector interests, and the new possibilities opened up by mobile technology and digital health.

The importance of both gender and accountability in health systems is undisputed as a way of improving health outcomes and as a moral imperative. What is less well understood is how gender and accountability interact, what mutual benefits and tensions exist, and what opportunities there are for developing gender-transformative accountability processes that address and transform unequal gender norms, roles, and relations at all levels. This article explores these related areas, and the tensions within/between them, in relation to power and inequity, intersectionality, and empowerment. More specifically, it explores three key considerations regarding the relationship between gender and accountability, namely that: (1) power relations are critical to both gender and accountability and, while gender is a pervasive driver of inequity in health systems, accountability mechanisms can address and transform health systems to be more gender-equitable; (2) gender is only one dimension of marginalisation and intersects with other social stratifiers, such as race, class, education, etc. to create different experiences of vulnerability; and it is necessary to take account of how these stratifiers collectively shape accountability; and (3) while accountability mechanisms can be used to create systems of empowerment, empowerment is a prerequisite for bringing about accountability. We review each of these considerations in turn.

\section{Power and inequity}

Power relations are critical to both gender inequities and accountability mechanisms and, while gender is a pervasive driver of inequity in health systems, accountability mechanisms can be used to address and transform health systems to be more gender-equitable. 
The health system is a multifaceted and disparate entity, within which there are many and diverse aspects where both gender and accountability come together; for example, in the ways in which power relations between actors are experienced, both within and beyond the health system (Bloom et al. 2008; Dworkin, Ghandi and Passano 2017).

Nonetheless, debates that deal specifically with health system accountability often still fail to address gendered power relations (Brinkerhoff 2003, 2004; Murthy 2008; Waldman, Reed and Hrynick 2017), and work on gender and health systems seldom discusses accountability issues (Murthy 2010), with the exception of some scholars (see George 2003; George, Iyer and Sen 2005; Murthy and Klugman 2004).

Accountability relationships operate at many different levels in relation to the health system. Brinkerhoff and Bossert (2008) identify three different sets of accountability actors and relationships. One set concerns those actors who are relatively high up the health system - policymakers, senior government bureaucrats, and politicians who operate within, and in relation to, the health system. The second set of actors are those who are more distant from the central health system hierarchy, overseeing health-care facilities and outreach workers. The third set of actors refers to patients, users, communities, and citizens. The relationships between these three sets of actors are characterised by power relations, status, and influence, with the first two sets of actors tending to have considerably more power, status, and health knowledge than the third (Brinkerhoff and Bossert 2008).

These power relations and differential access to knowledge and information have, as Brinkerhoff (2003) recognises, implications for accountability. Expanding on these different levels of interaction between health system actors, Cleary and colleagues (2013) argue that accountability is also influenced by available resources, by the actors' perceptions and attitudes, and by the values, beliefs, and culture embedded within the health system. These factors result in imbalances of power and different accountability consequences at different moments in time and in different places. For example, in some cases, national priorities and health officials' preferences may override local processes and choices, while in others, a lack of trust between local users and health-care personnel may inhibit local people from challenging health-care personnel. In other cases, power relations, culture, values, and beliefs are further complicated by the blurred boundary between communities and health systems, as some community members also hold formal or informal health provision roles (see, for example, Mafuta et al. 2015).

Both Brinkerhoff (2003) and Cleary et al. (2013) recognise the importance of power relations for accountability, yet do not link the experience and impact of these to gender roles, relations, and inequities. The interactions between power and gender in health systems cannot, however, be overlooked. Gendered power relations exist at all three 
of these health system levels and inform who is able to engage (e.g. by influencing access to resources and norms around engagement), what the terms of engagement might be (e.g. what forms of engagement are acceptable for whom), how much ability different actors have to negotiate accountability (e.g. who has the power to hold another actor accountable), and who can meaningfully implement change (e.g. who has the power to implement changes in support of accountability practices). Accountability in health systems is complex, multifaceted, and 'encompasses a vast array of potential power relationships' (Cornwall, Lucas and Pasteur 2000: 3). These gendered power relations bias health system research and negatively impact health systems (Sen, Östlin and George 2007). The lack of consideration of gender inequities within health system accountability research, for example, is a gender bias in and of itself, resulting from a lack of recognition or understanding of its relative importance. As within all research, if something is not included, analysed, and/or measured, it is not addressed. Without understanding and analysis of the role of gender power relations and how it might affect research content, processes, and outcomes, research findings and subsequent interventions will be negatively skewed (Morgan et al. 2016).

In contrast to work on accountability, literature on gender and health systems critically analyses how gender roles and relations shape the experiences and room for manoeuvre of women as users, as community members, as low-level employees of the health system and, occasionally, as senior leaders (Percival et al. 2014; Dhatt et al. 2017; Morgan et al. 2016; Theobald et al. 2017), although this is not always linked to discussions on accountability. This research and literature calls attention to three characteristics of health systems: firstly, that the health system is itself a 'gendered structure', in which important policy actors are mainly male; secondly, that men do not tend to prioritise women's health issues; and thirdly, that women actors, in the levels of interaction identified by Brinkerhoff and Bossert above, experience issues and challenges - often ignored by the health system - which their male counterparts do not (Hulton et al. 2014; Pendleton et al. 2015), and largely feminised cadres often have less power and influence. Even when women policy actors do achieve levels of seniority, they still tend to have less power than their male colleagues and to be allocated less prestigious, 'softer', feminine ministries (environment, women, family, education, and even health) as opposed to the masculine, prestigious areas of finance and defence where decisions about funding are ultimately made (Paxton and Hughes 2017; Dhatt et al. 2017).

In their review of global public-private partnerships which had an emphasis on accountability, Hawkes, Buse and Kapilashrami (2017) revealed how gender inequity is poorly attended to despite widespread recognition of the significance of gender in relation to health status, exposure to health determinants and health behaviours, leadership within the health system, and responses to illness. Instead, public-private health partnerships favoured men on their governing bodies, neglected 
to report sex-disaggregated data for the projects, and failed to focus on ailments which had the highest burden of disease for both men and women (Hawkes et al. 2017). This failure was linked to a complex interplay of factors including protecting private partners' financial interests and the failure to use gender analysis to explore the structural and complex power relations that shape health determinants.

Thus, while approaches to health system accountability have recognised power relations between different sets of actors and levels within the health system, they have yet to acknowledge the pervasiveness of gender power inequities across these levels. As a result, while on the one hand researchers working on gender within health systems are not doing enough to explore and link accountability to power relations, on the other hand, research into health system accountability overlooks the significance of gender in relation to power relations. This results in missed opportunities for accountability mechanisms and processes to actively transform health systems to be more gender-equitable. This includes ensuring that accountability processes themselves - such as governing bodies and community advisory groups - are genderequitable (i.e. reasonable representation of different men and women), assessing whether services are equitably provided and distributed, and analysing whether the needs of all service users are met, including the most vulnerable and marginalised within different contexts.

\section{Intersectionality}

Gender is only one dimension of marginalisation and intersects with other social stratifiers, such as race, class, education, etc., to create different experiences of vulnerability; and it is necessary to take account of how these stratifiers collectively shape accountability.

Gender is only one dimension of oppression, marginalisation, and inequality. Intersectionality analysis is being increasingly embraced within the gender and health system literature. Intersectionality, as described by Springer, Hankivsky and Bates, is:

an approach that explores simultaneous intersections between aspects of social difference and identity (e.g. as related to meanings of race/ethnicity, Indigeneity, gender, class, sexuality, geography, age, disability/ability, migration status, religion) and forms of systemic oppression (e.g. racism, classism, sexism, ableism, homophobia) (2012: 1661).

Intersectionality originated as a result of Kimberlé Williams Crenshaw's critical observation that women in the USA could experience both legal and racial discrimination in simultaneously multiplicative, or 'reciprocally constructing' ways (Collins 2015: 2). Intersectionality theory points out, for example, that 'gender intersects with economic inequality, racial or ethnic hierarchy, caste domination, differences based on sexual orientation, and a number of other social markers' (Sen and Östlin 2008: 2). Focusing only on one social stratifier, such 
as economic inequalities, across households 'can seriously distort our understanding of how inequality works, and who actually bears much of its burdens' (ibid.).

Literature on accountability within the health system often focuses on generic categories of users and inadequately examines the differences that impact on users' experience of health system delivery. In so doing, users are homogenised and certain categories elevated to the norm (male, urban, educated, heterosexual users). Alternatively, in an attempt to include 'vulnerable and marginalised groups' in accountability mechanisms, such as community scorecards, token representatives from such groups - such as poor female, disabled male, young female, old male - are often included to represent an entire group of 'marginalised' people. These processes are often not appropriately critically analysed; for example, there is little consideration of how gendered power relations may affect the ability of different groups to participate and share their experiences and challenges. Analysis of community scorecards (CSCs) as a mechanism to enhance accountability within Afghanistan's health system, for example, focuses on disaggregating participation according to the binary categories of male and female and on community requests for female doctors (Edward et al. 2015), but fails to examine gendered power relations either in relation to accountability or in relation to health, access to health services, and health outcomes.

At the same time, certain sections of a population can also be stigmatised by health system staff, affecting their ability to engage in accountability measures; poor women, for example, may be labelled uneducated or illiterate, blamed for their failure to practise healthy behaviours and, as a consequence, not be able to productively contribute to accountability processes (George 2003). Moreover, women users may struggle to communicate with health service providers because of their lack of voice and asymmetric power relations (George 2003; George et al. 2005; Murthy and Klugman 2004; Mafuta et al. 2015). Women's increased reliance on the health system as a result of their reproductive roles may also negatively influence their willingness to hold service providers accountable when they experience poor services or discrimination, especially when accountability mechanisms do not effectively or sensitively include or empower women, and in particular women with limited voice, such as migrant women or women with disabilities.

Social accountability emphasises 'the extent and capability of citizens to hold politicians, policy makers and providers accountable and make them responsive to their needs' (Mafuta et al. 2015: 1). The most effective strategies for doing this, Fox argues, are 'mutually empowering coalitions of pro-accountability actors in both state and society' (2015: 347). He stresses the importance of having state actors who are able to listen and respond to citizen voice, and of having citizens engaging and demanding accountability. Yet, as suggested above, not all citizens are in the same position or equally able to do this: gendered power relations limit voice and decision-making space. The inability 
of some citizens to effectively participate, or the lack of inclusion of certain citizens, means that their unique needs and experiences may not be addressed in quality of care interventions or service provision improvements which result from accountability processes. For example, young women may not feel able to speak up if certain men (e.g. senior men to them, male family members or male partners, or men who occupy a supervisory position) are in the room, or a disabled woman's unique experience of discrimination may be disregarded for the sake of consensus. Implementers therefore need to ensure that power dynamics are effectively managed within accountability processes. Effective participation of marginalised and vulnerable categories within health system accountability processes may require additional activities and resources, including separate data collection exercises. CARE (2013) has produced some helpful guidance on including marginalised groups within CSC processes which may be applied to health system accountability. In its overview of gender inclusion and accountability, LMG (2014) recommends more gender disaggregation and the inclusion of women; it suggests that participation (and the corresponding politics) be articulated in ways that resonate with particular excluded peoples, and that partnerships and alliances be built which make politics more accessible to them.

While we know that gender is only one dimension of marginalisation, and interacts with other dimensions in complex and multifaceted ways, we do not yet have the tools to look at the intersections within health systems and in particular within accountability processes. More work is needed in terms of how we operationalise the complexity of power relations within the health system, and how this relates to the wider sociocultural environment to go beyond simply acknowledging that marginalisation exists. In addition, we need to know more about how privilege and disadvantage adhere at all levels and affect all actors within the health system, not just at the community or service delivery level.

\section{Empowerment}

While accountability mechanisms can be used to create systems of empowerment, empowerment is a prerequisite for bringing about accountability.

The term 'empowerment' encompasses both liberal and liberating components, focusing on both the ways in which individual women achieve greater self-actualisation and autonomy and on the collective consciousness required to transform gender structures (Cornwall and Sardenberg 2014; Sen and Östlin 2008). While both these components require attention to power dynamics, there is also an inherent tension between empowerment as an individual action that stems from within, and empowerment as collective conscientisation. The concept of relational empowerment, introduced by VanderPlaat, offers a lens for understanding empowerment for some through the actions of others. She argues that:

At the very heart of the concept of relational empowerment is the principle that one never can be just an empowerer or a person in 
need of empowerment... The ability to be empowering or to support someone else's capacity to be empowering grows out of the mutual recognition that all of us can contribute to the construction of knowledge and social change but that, in the process, all of us have a lot to learn. In a truly empowering process, everybody changes (VanderPlaat 1999: 777).

Engaging with the concept of empowerment thus always involves paying attention to power relations (Cornwall and Sardenberg 2014) and how they play out at multiple levels.

In her review of using accountability to improve reproductive health care, George recognises that incapacity and inferiority in relation to officialdom is a form of disempowerment. She thus stresses the importance of participation and argues that accountability measures that 'encourage the active participation of marginalised groups can support the assertiveness and empowerment of those who are socially excluded' (George 2003: 165).

Inclusion in accountability processes can nurture citizenship and foster a sense of agency and entitlement among those who are involved. According to George (2003), increased and better representation of marginalised groups - and the information, dialogue, and negotiation that accompanies this - can not only change how marginalised people see themselves, but also how service providers perceive these groups. ${ }^{5}$ In northern Ethiopia, for example, social accountability committees used community scorecards to monitor health service delivery; while also promoting women's increased participation, and offering training and support to facilitate their engagement in accountability initiatives (LMG 2014). Such empowerment therefore has the potential to contribute to better health and improved health systems by improving interactions between health providers and different types of clients, and through ensuring that all types of clients are agents and advocates in their own health care.

At the same time, however, empowerment can also be a prerequisite for bringing about accountability. For example, as stated above, certain sections of a population can be stigmatised and, by so doing, their ability to engage in accountability measures can be undermined. These subtle barriers to accountability are seldom recognised, even when accountability measures are sensitive towards social hierarchy and exclusion and foster both meaningful participation and empowerment (George 2003). Barasa and colleagues (2016) examine two Kenyan examples where community members occupied positions on the hospital management committees, which had oversight responsibilities for the hospitals. In both instances, these committees were seen as passive, disempowered bodies that merely approved hospital decisions. Several factors contributed to this, including: the power relations between hospital staff; hospital managers' convictions that community members were ill-equipped (illiterate, uneducated, unable to understand 
budgets, and too narrowly focused on personal experiences) to play a useful role; and as a result, this affected managers' power to minimise community engagement; managers' failure to interrogate whom from the community participated; and the consequent potential for elite community representatives to benefit from the information shared in committee meetings (Barasa et al. 2016).

The outcome was that community members were 'minimally involved' in the priority setting and resource allocation processes undertaken by the hospitals. Barasa and colleagues (2016: 11) conclude that 'there is still the need to put in place measures that ensure that these actors are empowered to participate' and to confirm that accountability processes do not inadvertently work to disempower those involved. Gender can also shape this. Recent work on governance and devolution in Kenya has also highlighted how gender power relations intersecting with health system hierarchies limit women's ability to actively participate in accountability mechanisms at both the county and community level (McCollum 2017).

This chicken-and-egg situation suggests that, while we know that there is a relationship between accountability and agency, we still do not know enough about how it flows. Does accountability lead to empowerment or empowerment lead to accountability? Moreover, how do gender and power relations shape these trajectories and intersect with other drivers of inequality? Clearly, more information is needed about how accountability and agency are co-constructed and related.

\section{A way forward}

In order to create lasting change which protects the health of all people, including those defined as poor, marginalised, and vulnerable, and recognises the gender-specific health needs of both men and women, we need to advance both theory and practice in relation to both gender and accountability. In particular, this article identifies three areas where this is critical: power relations, intersectionality, and empowerment. The importance of power relations and inequities is recognised in debates on gender and in accountability perspectives, yet not enough is being done to explore how to bring these together, and pursue an agenda of change that promises win-win situations which benefit both. In terms of intersectionality, gendered approaches to health systems have drawn attention to the importance of multiple social stratifiers and how these intersect to shape different people's vulnerability and health system needs. This sophisticated theorisation shows how social stratifiers can collectively and uniquely inform people's health needs, behaviours, and responses to accountability debates, and enhance understandings of how best to promote and use accountability mechanisms to meet the needs of different groups. And finally, empowerment, like power relations and intersectionality, is implicated in both gender and accountability, but there is little understanding of the ways in which these dynamics are co-produced, the synergies between them, and how they can best be realised and promoted. 
What is clear from this overview, however, is that researchers of health systems have neither the tools nor the indicators to conceptualise the full range and complexity of gender and accountability. Further work is required to ensure that all citizens, including those most marginalised, are engaged in the monitoring of health system provisions and to support health systems' managers and practitioners to recognise gender-related needs. Focusing on gender and accountability may mean that, even if accountability initiatives do not always achieve expected health-related outcomes (increased life expectancy, transparency of arrangements, improved health), they may produce other valued results. These include greater knowledge and understanding of health system functioning (including of power and gender dynamics), constraints, or political process alongside individual or community empowerment and may, in so doing, make health systems more equitable for men and women, people of other genders, marginalised populations, and for diverse communities.

\section{Notes}

* The authors would like to acknowledge support from Research in Gender and Ethics (RinGs): Building Stronger Health Systems [Project No PO5683]. RinGs is a partnership across three research consortiums (Future Health Systems, ReBUILD (Research for stronger health systems post-conflict) and RESYST (Resilient and Responsive Health Systems), all supported by the UK Department for International Development (DFID). The views expressed are not necessarily those of DFID. The authors would like to thank Asha George, Erica Nelson, and Kate Hawkins, and the anonymous reviewers, for their insightful comments on this article.

1 Institute of Development Studies.

2 Liverpool School of Tropical Medicine.

3 Johns Hopkins Bloomberg School of Public Health, Baltimore, MD.

4 Although often conceived of as the provision of health services, Gorsky and Sirrs define health systems as 'a holistic understanding of organized medicine, incorporating not only services but also labour force, financing, regulatory framework, patients, treatments, and health outcomes' (2017: 362). Bloom, Standing and Lloyd expand on this understanding, drawing attention to the ways in which health systems operate in low- and middle-income countries, their pluralistic nature formed through highly marketised systems, and the presence of knowledge assymetries. They argue that health systems should be recognised as 'knowledge economies which produce and mediate access to health knowledge embedded in people, services and commodities and which can potentially be organised in different ways. These ways encompass context-dependent factors, such as types of governance and relative strengths of states, and other factors such as changes in technologies and health needs' (2008: 2077). Other critical analyses of health systems emphasise the need for analysis to go beyond health, and to include more sociological analyses of corruption, human development, the construction of metrics, and policy (Gorsky and Sirrs 2017). 
5 George (2003) recognises the potential for accountability initiatives that promote collective consequences and foster participation, assertiveness, and empowerment amongst communities to produce negative results, as critical assessments of health system and service providers do not always address power relations. She proposes that other actors within the health system, such as non-governmental organisations, be involved to counteract negative consequences and challenge vested interests.

\section{References}

Alvarez-Dardet, C. and Vives-Cases, C. (2012) 'Three Waves of Gender and Health', Eurohealth 18.2: 4-7

Barasa, E.W.; Cleary, S.; English, M. and Molyneux, S. (2016) 'The Influence of Power and Actor Relations on Priority Setting and Resource Allocation Practices at the Hospital Level in Kenya: A Case Study', BMC Health Services Research 16: 536, https://doi.org/10.1186/ s12913-016-1796-5 (accessed 22 January 2018)

Bloom, G.; Standing, H. and Lloyd, R. (2008) 'Markets, Information Asymmetry and Health Care: Towards New Social Contracts', Social Science \& Medicine 66.10: 2076-87, https://doi.org/10.1016/j. socscimed.2008.01.034 (accessed 22 January 2018)

Brinkerhoff, D.W. (2004) 'Accountability and Health Systems: Toward Conceptual Clarity and Policy Relevance', Health Policy and Planning 19.6: 371-79, https://doi.org/10.1093/heapol/czh052 (accessed 22 January 2018)

Brinkerhoff, D.W. (2003) Accountability and Health Systems: Overview, Framework, and Strategies, Bethesda MD: The Partners for Health Reformplus Project, Abt Associates Inc.

Brinkerhoff, D.W. and Bossert, T.J. (2008) 'Health Governance: Concepts, Experience, and Programming Options', Health Systems 20/20 Policy Brief, Bethesda MD: Health Systems 2020

GARE (2013) Community Score Card Implementation Guidance Notes: Recommendations from CARE CSC Experts, Atlanta GA and London: CARE, http://familyplanning.care2share.wikispaces.net/file/view/ CSC_Technical.pdf (accessed 22 January 2018)

Cleary, S.M.; Molyneux, S. and Gilson, L. (2013) 'Resources, Attitudes and Culture: An Understanding of the Factors that Influence the Functioning of Accountability Mechanisms in Primary Health Care Settings', BMC Health Services Research 13.320: 1-1 1

Collins, P.H. (2015) 'Intersectionality's Definitional Dilemmas', Annual Review of Sociology 41: 1-20, https://doi.org/10.1146/annurevsoc-073014-112142 (accessed 22 January 2018)

Cornwall, A. and Sardenberg, C. (2014) 'Participatory Pathways: Researching Women's Empowerment in Salvador, Brazil', Women's Studies International Forum 45 (July-August): 72-80, https://doi.org/10.1016/j.wsif.2014.01.006 (accessed 22 January 2018)

Cornwall, A.; Lucas, H. and Pasteur, K. (2000) 'Introduction: Accountability hrough Participation: Developing Workable Partnership Models in the Health Sector', IDS Bulletin 31.1: 1-13, 
http://bulletin.ids.ac.uk/idsbo/article/view/1304 (accessed 22 January 2018)

Dhatt, R. et al. (2017) 'The Role of Women's Leadership and Gender Equity in Leadership and Health System Strengthening', Global Health, Epidemiology and Genomics 2: e8, doi:10.1017/gheg.2016.22 (accessed 22 January 2018)

Dworkin, S.L.; Gandhi, M. and Passano, P. (eds) (2017) Women's Empowerment and Global Health: A Twenty-First-Century Agenda, California CA: University of California Press

Edward, A. et al. (2015) 'Enhancing Governance and Health System Accountability for People Centered Healthcare: An Exploratory Study of Community Scorecards in Afghanistan', BMC Health Services Research 15: 299, https://doi.org/10.1186/s12913-015-0946-5 (accessed 22 January 2018)

Fox, J.A. (2015) 'Social Accountability: What Does the Evidence Really Say?', World Development 72 (August): 346-61

George, A. (2003) 'Using Accountability to Improve Reproductive Health Care', Reproductive Health Matters 11.21: 161-70

George, A.; Iyer, A. and Sen, G. (2005) Gendered Health Systems Biased Against Maternal Survival: Preliminary Findings from Koppal, Karnataka, India, IDS Working Paper 253, Brighton: IDS

Gorsky, M. and Sirrs, C. (2017) 'World Health by Place: The Politics of International Health System Metrics, 1924-c. 2010', fournal of Global History 12.3: 361-85, doi:10.1017/S1740022817000134 (accessed 22 January 2018)

Hawkes, S.; Buse, K. and Kapilashrami, A. (2017) 'Gender Blind? An Analysis of Global Public-Private Partnerships for Health', Globalization and Health 13: 26, doi:10.1186/s12992-017-0249-1 (accessed 22 January 2018)

Hulton, L. et al. (2014) 'Using Evidence to Drive Action: A "Revolution in Accountability" to Implement Quality Care for Better Maternal and Newborn Health in Africa', International Journal of Gynecology $\mathcal{E}^{\circ}$ Obstetrics 127.1: 96-101, http://dx.doi.org/10.1016/j.ijgo.2014.07.003 (accessed 22 January 2018)

LMG (2014) Cultivating Accountability for Health Systems Strengthening, Leadership, Management \& Governance (LMG) Project, www.lmgforhealth.org/Govern4HealthApp/cultivatingaccountability (accessed 22 January 2018)

Mafuta, E.M. et al. (2015) 'Social Accountability for Maternal Health Services in Muanda and Bolenge Health Zones, Democratic Republic of Congo: A Situation Analysis', BMC Health Services Research 15: 514, doi:10.1186/s12913-015-1176-6 (accessed 22 January 2018)

McCollum, R. (2017) 'Process, Power and Politics: Setting Priorities for Community Health and Equity in the Recently Devolved Kenyan Health System', PhD thesis, Liverpool School of Tropical Medicine

Morgan, R. et al. (2016) 'How to Do (or Not to Do)... Gender Analysis in Health Systems Research', Health Policy and Planning 31.8: 1069-78, doi:10.1093/heapol/czw037 (accessed 22 January 2018) 
Murthy, R.K. (2010) 'Accountability to Citizens on Gender and Health', in G. Sen and P. Östlin (eds), Gender Equity in Health: The Shifting Frontiers of Evidence and Action, New York NY: Routledge

Murthy, R.K. (2008) 'Strengthening Accountability to Citizens on Gender and Health', Global Public Health 3: 104-20, doi:10.1080/17441690801900852 (accessed 22 January 2018)

Murthy, R.K. and Klugman, B. (2004) 'Service Accountability and Community Participation in the Context of Health Sector Reforms in Asia: Implications for Sexual and Reproductive Health Services', Health Policy and Planning 19.1: i78-i86

Paxton, P. and Hughes, M.M. (2017) Women, Politics, and Power: A Global Perspective, Thousand Oaks CA: SAGE Publications

Pendleton, J.; Irani, L.; Mellish, M.; Mbuya-Brown, R. and Yinger, N. (2015) Promoting Gender-Responsive Health Governance: Lessons and Next Steps, Washington DC: Futures Group, Health Policy Project

Percival, V.; Richards, E.; MacLean, T. and Theobald, S. (2014) 'Health Systems and Gender in Post-Conflict Contexts: Building Back Better?', Conflict and Health 8: 19

Sen, G. and Östlin, P. (2008) 'Gender Inequity in Health: Why It Exists and How We Can Change It', Global Public Health 3 (Supplement 1): 1-12, https://doi.org/10.1080/17441690801900795 (accessed 22 January 2018)

Sen, G.; Östlin, P. and George, A. (2007) Unequal, Unfair, Ineffective and Inefficient - Gender Inequity in Health: Why It Exists and How We Can Change It, Final Report to the WHO Commission on Social Determinants of Health by the Women and Gender Equity Knowledge Network, Bangalore and Stockholm: Indian Institute of Management Bangalore and Karolinska Institutet

Springer, K.W.; Hankivsky, O. and Bates, L.M. (2012) 'Gender and Health: Relational, Intersectional, and Biosocial Approaches', Social Science E̊ Medicine 74.11: 1661-666, https://doi.org/10.1016/j. socscimed.2012.03.001 (accessed 22 January 2018)

Theobald, S. et al. (2017) 'The Importance of Gender Analysis in Research for Health Systems Strengthening', Health Policy and Planning 32 (Supplement 5): v1-v3

VanderPlaat, M. (1999) 'Locating the Feminist Scholar: Relational Empowerment and Social Activism', Qualitative Health Research 9.6: 773-85

Waldman, L.; Reed, P. and Hrynick, T. (2017) Accountability in Health Systems and the Potential of mHealth, IDS Working Paper 490, Brighton: IDS

WHO (2016) Gender, Women and Health: What Do We Mean By 'Sex' and 'Gender'?, World Health Organization, www.legal-tools.org/doc/ a33dc3/pdf/ (accessed 31 January 2018) 
